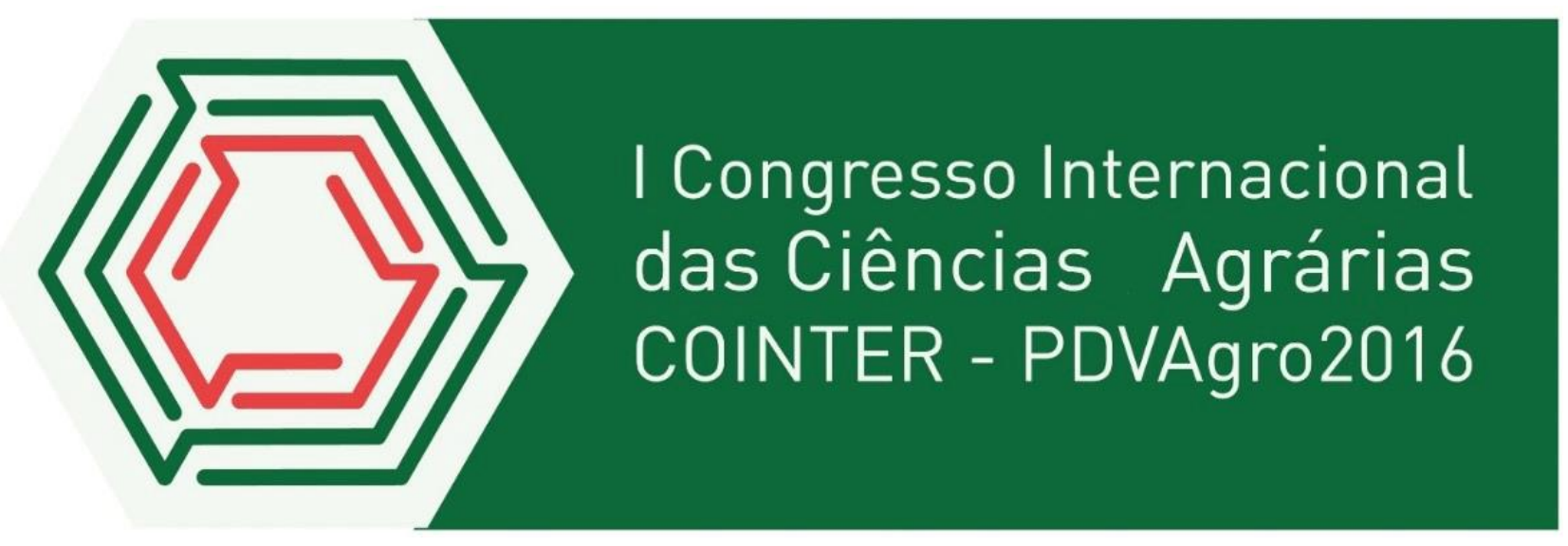

\title{
PALMA FORRAGEIRA E CAJU, SUAS APTIDÕES E ZONEAMENTO AGROCLIMÁTICO PARA O MUNICÍPIO DE RECIFE
}

Apresentação: Comunicação Oral

Raimundo Mainar de Medeiros ${ }^{1}$; Romildo Morant de Holanda $^{2}$; Gleide de Lima Ferreira ${ }^{3}$

\begin{abstract}
Resumo
A aptidão climática destina-se a caracterizar os parâmetros meteorológicos que mais atuam no comportamento das culturas e, que em suas condições extremas, venham a prejudicar sensivelmente o crescimento e o desenvolvimento da planta. Objetiva-se realizarem as aptidões e os zoneamentos agroclimáticos para as culturas da palma forrageira e o potencial produtivo do cultivo do caju com base em indicadores de clima estabelecidos de acordo com as exigências das culturas. Os dados de precipitações e da temperatura média compensada do ar utilizada consistiram da série histórica do período de 1962-2015. Para análise dos dados foi utilizado um programa em planilha eletrônica. Os referidos dados foram adquiridos do Instituto Nacional de Meteorologia (INMET, 2015). As distribuições pluviométricas ocorrem de forma irregular e com variação durante todos os anos. Essas séries foram selecionadas com base no critério de analisar apenas aquelas sem falhas e contínuas, bem como distribuídas homogeneamente na área de estudo, para as séries que continham falhas, utilizou-se o método de preenchimento. Realizou-se o cálculo do balanço hídrico climatológico para a capacidade de campo de $100 \mathrm{~mm}$, obtendo-se os índices de umidade, aridez e hídrico, as atividades fisiológicas da palma forrageira e do caju para o município do Recife - PE. Para o grande Recife as atividades fisiológicas da palma forrageira são bastantes restritas devido às condições inadequadas da disponibilidade de temperatura e do índice de umidade, como foi verificado apresentando-se dentro da faixa restrita ou inapta ao desenvolvimento da cultura. A técnica de classificação e aptidões climática utilizando dos índices de deficiência hídricas para o município Recife não fornecem subsídios de alta confiabilidade para a classificação e aptidão do caju.
\end{abstract}

Palavras-Chave: Deficiência e excedente hídrico, evapopluviograma, irrigação e forragem.

\section{Introdução}

\footnotetext{
${ }^{1}$ Dr. Em Meteorologia, Pesquisador da Universidade Federal Rural de Pernambuco, e-mail:mainarmedeiros@gmail.com ${ }^{2}$ Prof. Dr. Universidade Federal Rural de Pernambuco, UFRPR, e-mail: romildomorant@gmail.com

${ }^{3}$ Mestranda em Engenharia Ambiental, UFRPE, e-mail: gleidelima@ hotmail.com
} 
A precipitação pluviométrica no Nordeste Brasileiro (NEB) é resultante do acoplamento de vários sistemas atmosféricos de várias escalas quase periódicos, como a Zona de Convergência Intertropical conforme UVO (1989), os Vórtices Ciclônicos de Ar Superior em conformidade com os autores Kousky e Gan (1981), os Sistemas Frontais descritos por Kousky (1979) e os Distúrbios de Leste referenciados pelo Espinoza (1996), que podem ser modificados pelas características fisiográficas da região e por anomalias atmosféricas de escala planetária, destacando-se o dipolo do Atlântico e o El Niño-Oscilação Sul (ENSO), que modificam a frequência, distribuição espacial e intensidade desses sistemas, afetando diretamente a agricultura, a pecuária, irrigação e os recursos hídricos de acordo com Araújo et al. (2006), diante do exposto, o conhecimento do comportamento das variáveis climáticas é de suma importância para o planejamento das atividades agrícolas. E a temperatura do ar destaca-se na condução de estudos concernentes à ordenação agrícola, uso do solo, zoneamento ecológico e aptidão climática, época de semeadura, estimativa do ciclo das culturas, dentre outras conforme Oliveira Neto et al. (2002).

Para o desenvolvimento das culturas é necessário o uso adequado da água, o déficit ou o excesso hídrico podem influenciar na produção agrícola de determinada localidade ou de uma região. Bergamaschi et al. (2004) verificaram que a produtividade de culturas agrícolas é fortemente dependente das precipitações, sobretudo quando se trata de cultura de sequeiro, o déficit ou excesso hídrico pode comprometer o preparo do solo, e toda a sua cadeia produtiva.

A palma forrageira (Opintia sp.) é um membro da família das Cactáceas, cultivada em todo o mundo, exceto na Antártica, em mais de 1.000.000ha, principalmente para a produção de frutas e forragem, além do uso como planta ornamental de acordo com Reyes-Agüero et al. (2006). Embora possua reconhecida gama de potencialidades, a palma forrageira tem sido cultivada no Semiárido Brasileiro quase exclusivamente para a produção de forragem em conformidade com os autores Santos et al. (2001); Araújo et al. (2005); Pinto et al. (2011) e de acordo com Bezerra et al. (2014) se tornou, ao longo das décadas, uma das principais alternativas para alimentação dos rebanhos, sobretudo em longos períodos de estiagem, quando as pastagens nativas e outras forrageiras, tais como as gramíneas e leguminosas de elevada exigência hídrica, estão sob fortes condições de estresse hídrico.

A palma forrageira é considerada uma importante aliada na sustentabilidade e na redução da vulnerabilidade das atividades agropecuárias no Semiárido Brasileiro. De acordo com Moura et al. (2011) embora se tenha referência, na literatura, sobre as condições climáticas favoráveis ao cultivo da palma forrageira por se tratar de uma cultura com grandes oportunidades de adaptabilidade às condições de semiaridez, seu cultivo tem sido realizado sem que haja um embasamento técnicocientífico no que concerne às suas necessidades climáticas. 
Conhecer o clima local é um fator importante para planejar os recursos hídricos, haja vista que vários elementos meteorológicos estão inseridos no ciclo hidrológico de acordo com Medeiros et al. (2013). Avaliaram a estimativa dos balanços hídricos climatológicos (BHC) e suas classificações segundo Köppen, Thornthwaite e Mather (1948; 1953) para a área da bacia hidrográfica do rio Uruçuí Preto, PI (BHRUP). Os meses de maiores insolação ocorrem entre maio a outubro com flutuações variando de 223 horas e décimos a 297,1 horas e décimos. A umidade relativa do ar oscila entre $60 \%$ a $80 \%$ nos meses de novembro a maio. A retirada de água na área da BHRUP ocorrem nos meses de agosto a janeiro, as deficiências hídricas ocorrem entre os meses de outubro a janeiro, a reposição das águas acontecem nos meses de fevereiro e março e os excedentes hídricos ocorrem entre os meses de abril a julho, onde a comunidade ribeirinha utiliza-se de sistema de irrigação nas atividades agrícolas independente dos períodos seco ou chuvoso.

Wollmann e Galvani (2013) relatam que as condições locais hídricas e de clima, são levadas em consideração no zoneamento agroclimático, visando à exploração de culturas economicamente rentáveis. Toledo et al. (2009) comentam que a aptidão de uma dada região é definida com base na associação da precipitação, temperatura e altitude local, estas informações são de grande importância.

Segundo Pereira et al. (2002) e Horikoshi (2007), a água disponível para o consumo e uso do homem pode ser quantificada pelo balanço hídrico climatológico, em que fica evidente a variação temporal de períodos com excedente e deficiência hídricas, permitindo, dessa forma, o planejamento agrícola. O mapeamento de variáveis que compõem o balanço hídrico é fundamental para o planejamento de técnicas do uso da terra e para entender, explicar e prever o crescimento e o desenvolvimento dos recursos naturais, com a finalidade de promover a sua utilização racional.

A cultura do caju (Anacardium occidentale L.) é uma planta tropical, originária do Brasil, difundida em quase todo o território e é amplamente praticada no NEB, sendo considerado um produto de exportação que enriquece a economia regional de acordo com Severino (2008). Entretanto, segundo Pereira et al. (2007), apesar do amplo cultivo dessas cultivares no NEB, há ainda poucos estudos de zoneamento agrícola em alguns estados produtores de caju.

O NEB, possui uma área plantada de caju superior a 650 mil hectares, correspondendo a mais de 95\% da produção nacional, sendo os Estados do Ceará, Piauí, Rio Grande do Norte e Bahia os principais produtores segundo Oliveira et al. (2003).

O estudo da variabilidade espaço-temporal de longas séries meteorológicas, além de contribuir indicando quais as áreas mais propícias ao plantio/semeadura de culturas, indica também os períodos, além de trazer informações extremamente importantes sobre possíveis descontinuidades climáticas, tendências ou periodicidades, auxiliando o estudo das forçantes moduladoras das condições meteorológicas em uma região conforme Blain (2009). 
Medeiros et al (2015) caracterizar o clima e efetivaram o zoneamento agroclimático para 11 culturas apontando as suas possíveis aptidões de cultivo para o município de Barbalha - CE. Utilizaram-se da série histórica de precipitação e temperatura do ar média para a realização do cálculo do balanço hídrico climatológico, classificação climática, construção do evapopluviograma e o zoneamento agroclimático das culturas. Constataram deficiência hídrica anual de $654,4 \mathrm{~mm}$, ocorrendo excesso hídrico anual de 245,8 mm nos meses de fevereiro a abril. Os índices de aridez, umidade e hídrico foram 44,50, 16,71 e $-9,99 \%$, respectivamente. A região estudada possui aptidão plena para os cultivos de abacaxi, algodão herbáceo, feijão, mamona, mandioca e sisal. Para o cultivo de caju, milho e sorgo contatou-se aptidão moderada. Apenas o cultivo da banana e cana-de-açúcar foi restrito devido à região apresentar déficit hídrico acentuado.

Objetiva-se realizarem as aptidões e os zoneamentos agroclimáticos para as culturas da palma forrageira (Opuntia sp) e o potencial produtivo do cultivo do caju, (Anacardium occidentale L.) com base em indicadores de clima estabelecidos de acordo com as exigências das culturas.

\section{FUNDAMENTAÇÃO TEÓRICA}

\section{MATERIAL e MÉTODOS}

Recife localiza-se na latitude $08^{\circ} 01^{\prime} \mathrm{S}$ e de Longitude $34^{\circ} 51^{\prime} \mathrm{W}$, com altitude média de 72 metros. Limita-se ao norte com as cidades de Olinda e Paulista, ao sul com o município de Jaboatão dos Guararapes, a oeste com São Lourenço da Mata e Camaragibe, e a leste com o Oceano Atlântico.

A Zona de Convergência Intertropical (ZCIT) atinge o Recife, principalmente no outono, e causa chuvas com trovoadas e mudança na direção dos ventos de SE para NE, ou mesmo, calmarias. Devido à irregularidade espaço temporal de sua ocorrência, sua ocorrência de ano para ano é sujeita à grande variabilidade em conformidade com Pernambuco (2006). As formações dos sistemas de Vórtices Ciclones de Altos Níveis (VCAS) quando de suas formações nos meses de fevereiro a abril e com suas bordas sobre o NEB em especial acima do estado do Pernambuco aumenta a cobertura de nuvem e provocam chuvas de alta intensidade e curto intervalo de tempo, causando prejuízo às comunidades como alagamento, enchentes, inundações e ao setor socioeconômico. As fortes chuvas que ocorrem na região, no período chuvoso, são influenciadas pela massa equatorial continental, que condiciona movimentos convectivos dos alísios de Nordeste e Sudeste, Zona de Convergência Intertropical (ZCIT), os efeitos da brisa marítima/terrestre e a temperatura da superfície do mar, no período seco a precipitação registrada é causada pelas contribuições locais formando nuvem seguida de precipitações isoladas. 
Os dados de precipitações e da temperatura média compensada do ar utilizada consistiram da série histórica do período de 1962-2015. Para análise dos dados foi utilizado um programa em planilha eletrônica. Os referidos dados foram adquiridos do Instituto Nacional de Meteorologia (INMET, 2015). As distribuições pluviométricas ocorrem de forma irregular e com variação durante todos os anos. Essas séries foram selecionadas com base no critério de analisar apenas aquelas sem falhas e contínuas, bem como distribuídas homogeneamente na área de estudo, para as séries que continham falhas, utilizou-se o método de preenchimento.

De acordo com a classificação climática de Köppen Recife e classificado como o clima Am clima de monção.

O cálculo do balanço hídrico climatológico (BHC) foi realizado através da metodologia proposta por Thornthwaite e Mather (1948, 1955), com elaboração de planilhas eletrônicas em conformidade com Medeiros (2014) que contabilizam as entradas e saídas de água no solo, em que a precipitação representa (ganho) e a evapotranspiração (perda) de umidade do solo, podendo-se estimar os valores correspondentes ao Excedente Hídrico (EXE) e Deficiência Hídrica (DEF). Com base nesta metodologia foi estimada a capacidade de armazenamento de água disponível no solo (CAD) de 100 mm. A Evapotranspiração Potencial (ETp) foi obtida conforme a Equação.

$$
E T p=F_{c} \cdot 16 \cdot\left(10 \frac{T}{I}\right)^{a}
$$

Em que;

ETp - Evapotranspiração potencial anual $\left(\mathrm{mm} \mathrm{ano}^{-1}\right)$;

Fc - Fator de correção, segundo a Tabela 1;

$\mathrm{T}$ - Temperatura média mensal $\left({ }^{\circ} \mathrm{C}\right)$;

I - Índice anual de calor, correspondente a soma dos doze índices mensais; e

a - Função cúbica do índice anual de calor dada por:

$$
\mathrm{a}=6,75^{*} 10^{-7} * \mathrm{I}^{3}-7,71 * 10^{-5} * \mathrm{I}^{2}+0,01791 * \mathrm{I}+0,492 .
$$

Tabela 1. Fator de Correção de acordo com Thornthwaite (1948) em função de todos os meses do ano.

Fator de Correção

\begin{tabular}{cccccccccccc} 
Jan & Fev & Mar & Abr & Mai & Jun & Jul & Ago & Set & Out & Nov & Dez \\
\hline 1,80 & 0,97 & 1,05 & 0,99 & 1,01 & 0,96 & 1,00 & 1,01 & 1,00 & 1,06 & 1,05 & 1,10
\end{tabular}

Fonte: UNESCO (1982).

Na determinação da aptidão climática para a cultura da palma forrageira (Opuntia sp.), foram utilizados os indicadores climáticos propostos por Souza et al. (2008) e expostos na Tabela 2. Essas 
faixas foram utilizadas no estudo do zoneamento agroclimático da palma forrageira para o estado de Pernambuco por Moura et al. (2011) e por Bezerra et al. (2014) e também em estudo sobre o zoneamento agroclimático da palma forrageira para o estado da Paraíba.

Na Síntese da aptidão e exigências climáticas da cultura do caju de acordo com Ometto (1981), aplicada a quatro tipos de aptidão: Plena; Moderada; Restrita e Inapta, para tanto se levou em consideração a flutuabilidade da deficiência hídrica municipal e realizou-se a classificação como mostrado nas Tabelas 3 e 4. (Ometto, 1981 e Aguiar et al. 2000).

Por meio do balanço hídrico, calcularam-se os índices de aridez, umidade e hídrico, conforme as equações abaixo. Estes índices são importantes para a caracterização climática da região segundo a metodologia de Thornthwaite (1948), e no estudo de adaptação de culturas à região em estudo.

O Índice de Aridez caracteriza-se por indicar a deficiência hídrica expressa em percentagem da evapotranspiração potencial (necessidade). É definido em função da deficiência e evapotranspiração potencial (ambas anuais), expresso da seguinte forma:

$$
I a=100 \frac{\sum D E F}{\sum E T p}
$$

O índice de umidade representa o excesso hídrico expresso em percentagem da necessidade que é representada pela evapotranspiração potencial, ambas anuais, segundo a expressão:

$$
I h=100 \frac{\sum E X E}{\sum E T p}
$$

Geralmente tem-se durante o ano estações de excesso e falta de água. Por isso, define-se o índice hídrico da seguinte maneira:

$$
I u=I h-0,6 \cdot I a
$$

Em que:

Ia - Índice de aridez (\%);

Ih - Índice hídrico (\%);

$\mathrm{Iu}$ - Índice de umidade (\%);

$\sum \mathrm{DEF}$ - Somatório da deficiência hídrica anual $\left(\mathrm{mm} \mathrm{ano}^{-1}\right)$;

$\sum$ EXE - Somatório do excedente hídrico anual $\left(\mathrm{mm} \mathrm{ano}^{-1}\right) ; \mathrm{e}$ 
$\sum$ ETp - Somatório da evapotranspiração anual $\left(\mathrm{mm} \mathrm{ano}^{-1}\right)$.

Os valores dos indicadores climáticos para o município do Recife foram aplicados em conformidade a Tabela 2 para determinação da aptidão climática, classificando a cultura da palma forrageira em aptidão plena, aptidão restrita e aptidão inaptidão.

Para a aptidão e zoneamento agroclimático utilizou-se dos critérios para classificação descritos por Moura et al. (2011) e referenciado por Bezerra et al. (2014), da seguinte forma:

a) Plena: A região possui clima adequado ao desenvolvimento da cultura, sem apresentar nenhuma restrição ao crescimento e desenvolvimento da cultura.

b) Restrita: O cultivo da palma forrageira nesta região é limitado no mínimo por um dos indicadores climáticos.

c) Inaptidão: Nesta região os indicadores climáticos encontram-se fora das faixas adequadas ao desenvolvimento da cultura.

d) Tabela 2. Aptidão e indicadores climáticos da cultura da palma forrageira.

\begin{tabular}{ccc}
\hline Plena & Restrita & Inaptidão \\
\hline $16,1 \leq$ Tméd $\leq 25,4$ & Tméd $<16,1 ;$ Tméd $>25,4$ & - \\
$28,5 \leq$ máx $\leq 31,5$ & Tmáx $<28,5 ;$ Tmáx $>31,5$ & - \\
$8,6 \leq$ Tmín $\leq 20,4$ & Tmín $<8,6 ;$ Tmín $>20,4$ & - \\
$10,0 \leq$ AMT $\leq 17,2$ & AMT $<10,0 ;$ AMT $>17,2$ & - \\
$368,4 \leq$ Prec $\leq 812,4$ & Prec $<368,4 ; 812,4<$ Prec $\leq 1089,9$ & Prec $>1089,9$ \\
$-65,6 \leq$ Iu $\leq-31,8$ & $-31,8<$ I $\leq 7,7 ;$ Iu $<-65,6$ & Iu $>7,7$ \\
\hline
\end{tabular}

e) Fonte: Souza et al. (2008).

f) Legenda: Tméd=Temperatura média; Tmáx=Temperatura máxima; Tmín=Temperatura mínima; AMT=Amplitude térmica; Prec =Precipitação média anual; Iu=Índice de umidade; (-) sem informações.

Para a aptidão e zoneamento agroclimático do caju utilizou-se dos critérios para classificação descritos por Ometto (1981) e dos Fatores de indicadores climáticos e referenciado por Aguiar et al. (2000), da seguinte forma expressos nas tabelas 3 e 4:

Tabela 3. Síntese da aptidão e exigências climáticas da cultura de acordo com Ometto (1981).

\begin{tabular}{clll}
\hline Plena & $\begin{array}{l}\mathrm{I}_{\mathrm{h}}>-10 \\
\mathrm{DEF}<100 \mathrm{~mm}\end{array}$ & $\begin{array}{l}\text { Em geral não há limitações climáticas para a } \\
\text { cultura, principalmente nas regões de clima } \\
\text { quente. }\end{array}$ \\
\hline Caju & $\begin{array}{l}\mathrm{I}_{\mathrm{h}}<-10 \\
100<\mathrm{DEF}<200 \mathrm{~mm} \\
200<\mathrm{DEF}<700 \mathrm{~mm}\end{array}$ & $\begin{array}{l}\text { Ocorrência normal de pequena deficiência } \\
\text { hídrica. } \\
\text { Cultivo parcial prejudicado pela deficiência } \\
\text { hídrica. }\end{array}$ \\
\hline Restrita & $700<\mathrm{DEF}<900 \mathrm{~mm}$ & $\begin{array}{l}\text { Deficiência hídrica severa na maioria dos solos. } \\
\text { Cultivo somente através de suprimento d'água } \\
\text { por irrigação. }\end{array}$ \\
\hline Inaptidão & $\mathrm{DEF}>700 \mathrm{~mm}$ & Suprimento hídrico insuficiente para a cultura. \\
\hline
\end{tabular}


Na Tabela 3 tem-se a Síntese da aptidão e exigências climáticas da cultura do caju de acordo com Ometto (1981), aplicada a quatro tipos de aptidão: Plena; Moderada; Restrita e Inapta, para tanto se levou em consideração a flutuabilidade da deficiência hídrica municipal e realizou-se a classificação como mostrado na referida tabela. A tabela tem-se as flutuações dos fatores e indicadores climáticos para a cultura do Cajueiro conforme adaptação de Aguiar et al (2000).

Tabela 4. Fatores e indicadores climáticos para a cultura do Cajueiro.

\begin{tabular}{|c|c|c|c|}
\hline \multicolumn{4}{|c|}{ Faixas de Aptidão } \\
\hline Fatores climáticos & Ideal & Tolerável & Não indicado \\
\hline$\overline{\text { Faixa Térmica }\left({ }^{\circ} \mathrm{C}\right)}$ & $19-34$ & $34-40$ & $<15$ \\
\hline Precipitação $\left(\mathrm{mm} \mathrm{ano}^{-1}\right)$ & $800-1500$ & $600-800$ & $<500$ \\
\hline Umidade Relativa do ar $(\%)$ & $65-85$ & $40-65<4$ & \\
\hline
\end{tabular}

Fonte: Adaptado de Aguiar et al. (2000).

\section{Resultados e Discussão}

As variáveis utilizadas na determinação do balanço hídrico climatológico (BHC) para o período de 1962-2015 encontram-se na tabela 5. Considerando a capacidade de armazenamento de água disponível (CAD) $100 \mathrm{~mm}$. A quantidade de água evapotranspirada é expressa pela evapotranspiração real (ETR), que se comportou de forma irregular à distribuição da precipitação pluvial.

Através do balanço hídrico climatológico foi possível determinar os índices de aridez (Ia), umidade (Iu), hídrico (Ih) e o CV, onde o CV é a concentração da evapotranspiração potencial na estação quente, determinada pelos três meses consecutivos de temperatura mais elevada do ano (trimestre mais quente). Tais índices determinam a classificação climática, baseada em observações e estudos realizados nas condições do Sudeste árido dos Estados Unidos da América e aplicado ao resto do mundo, proposto por Thornthwaite (1948).

Tabela 5. Variáveis utilizadas na elaboração das aptidões e dos zoneamentos agroclimático e na determinação do balanço hídrico climatológico.

\begin{tabular}{cccccccccc}
\hline \multirow{2}{*}{ Meses } & Tméd & Tmáx & Tmín & AMT & PREC & ETp & EVr & DEF & EXC \\
\cline { 2 - 9 } & \multicolumn{9}{c}{$\left({ }^{\circ} \mathrm{C}\right)$} \\
Jan & 26,7 & 30,5 & 22,7 & 7,8 & 79,9 & 144,9 & 82,3 & 62,5 & 0,0 \\
Fev & 26,9 & 30,5 & 22,9 & 7,6 & 113,7 & 136,4 & 114,2 & 22,2 & 0,0 \\
Mar & 26,7 & 30,5 & 22,9 & 7,6 & 191,1 & 146,6 & 146,6 & 0,0 & 0,0 \\
Abr & 26,2 & 29,8 & 22,7 & 7,1 & 243,6 & 129,0 & 129,0 & 0,0 & 61,2 \\
Mai & 25,5 & 29,2 & 22,2 & 7,0 & 300,1 & 119,4 & 119,4 & 0,0 & 180,7 \\
Jun & 24,6 & 28,2 & 21,8 & 6,4 & 318,1 & 101,3 & 101,3 & 0,0 & 216,7 \\
Jul & 24,0 & 27,6 & 21,0 & 6,6 & 287,9 & 96,0 & 96,0 & 0,0 & 191,9 \\
Ago & 24,1 & 27,7 & 20,7 & 7,0 & 174,8 & 97,6 & 97,6 & 0,0 & 77,2 \\
Set & 24,9 & 28,3 & 21,3 & 7,0 & 85,2 & 107,3 & 105,1 & 2,3 & 0,0
\end{tabular}




\begin{tabular}{cccccccccc} 
Out & 25,7 & 29,3 & 21,9 & 7,4 & 49,7 & 127,5 & 93,0 & 34,4 & 0,0 \\
Nov & 26,3 & 30,0 & 22,3 & 7,7 & 37,1 & 135,7 & 60,2 & 75,5 & 0,0 \\
Dez & 26,7 & 30,4 & 22,6 & 7,8 & 49,4 & 148,5 & 58,0 & 90,5 & 0,0 \\
\hline
\end{tabular}

Legenda: Tméd - Temperatura média; Tmáx - Temperatura máxima; Tmín - Temperatura mínima; AMT - Amplitude térmica, Prec - Precipitação média anual; ETp - Evapotranspiração potencial, EVr - Evapotranspiração real, DEF - Deficiência hídrica e EXC - Excesso Hídrico.

A Tabela 5 representa o balanço hídrico climatológico médio do município Recife. A temperatura média oscila entre $24{ }^{\circ} \mathrm{C}$ no mês de julho a $26,7{ }^{\circ} \mathrm{C}$ nos meses de dezembro, janeiro e março com uma temperatura média anual de $25,7^{\circ} \mathrm{C}$. As amplitudes térmicas oscilam entre $6,4^{\circ} \mathrm{C}$ a $7,8^{\circ} \mathrm{C}$. Os meses de junho e julho registram as menores amplitudes térmicas e as maiores amplitudes ocorrem nos meses de novembro a janeiro, resultados concordantes com o trabalho de Medeiros et al. (2013).

A precipitação média anual é de $1.174,7 \mathrm{~mm}$, o quadrimestre chuvoso centra-se nos meses de abril, maio, junho e julho com flutuação entre 243,6 a 318,1 mm.mês ${ }^{-1}$, o quadrimestre seco ocorre nos meses de outubro a janeiro e fluem entre 37,1 a 79,9 mmmês $^{-1}$.

A evapotranspiração potencial anual é de $1.490,2 \mathrm{~mm}$, o quadrimestre com maiores valores evaporativo ocorre nos meses de dezembro a março, registrando-se valores oscilando entre 136,4 a 148,5 mm. A oscilação mensal de ETp flui entre 96 a 148,5 mm. Nos meses de julho e agosto registram-se os menores índices evaporativos com 96 e 97,6 mm respectivamente.

A evaporação real anual é de 1.202,9 mm, os meses de maiores valores evaporativos ocorrem entre fevereiro a junho e setembro com flutuação entre 101,3 a 146,6 mm e nos meses de novembro, dezembro e janeiro acontecem os menores poder evaporativo com oscilação entre 58 a 82,3 mm.

As deficiências hídricas ocorrem entre os meses de setembro a fevereiro com valor anual de 287,4 mm e os excedentes hídricos ocorrem nos meses de abril a agosto com índice anual de 727,6 mm. O município de Recife tem os seus respectivos índices: Umidade de 19,28\%, Aridez com 0,19\% e o hídrico com $0,37 \%$.

Guerra et al. (2005), constataram que os genótipos da palma forrageira e suas variedades miúda, redonda e gigante, apresentaram maior rendimento nas regiões com precipitação pluviométrica média de $700 \mathrm{~mm} \mathrm{ano}^{-1}$. Segundo Rocha (2012), a faixa adequada de precipitação pluviométrica ao desenvolvimento da palma forrageira está entre 368,4 e 812,4 mm, embora possa ser cultivada com $200 \mathrm{~mm}$.

Medeiros et al. (2015) descrevem que as precipitações ocorridas no estado do Piauí de junho a setembro são caracterizadas como abaixo da evapotranspiração, não sendo suficiente para atender a demanda ocorrida no período, tornando inviável a produção agrícola de sequeiro e com pouca 
contribuição para o armazenamento de água no solo, detalha-se que esta variabilidade ocorrem para o município de Recife nos meses de outubro a janeiro com a evaporação conforme tabela 5.

Para certificar-se de melhor produtividade nas culturas, é indispensável o uso de sistemas de irrigação em regiões que apresentam deficiência hídrica que limitar o desenvolvimento das culturas, principalmente quando esta deficiência estende por todos os meses do ano conforme afirmação de Santos et al. (2010).

Marengo et al. (2004) afirma que o comportamento da deficiência hídrica no planejamento agrícola, para uma agricultura segura e economicamente viável, recomenda-se a utilização de sistemas de irrigação. Para efetuar o planejamento dos cultivos e o manejo a ser realizado durante o ciclo das culturas, é importante o conhecimento histórico das variáveis climáticas da região, analisando cuidadosamente a variabilidade da precipitação e a intensidade da evapotranspiração, podendo reduzir ao máximo a ocorrência de déficit hídrico.

Wollmann e Galvani (2013) relatam que as condições locais hídricas e de clima, são levadas em consideração no zoneamento agroclimático, visando à exploração de culturas economicamente rentáveis. São estas as características agroclimáticas desta localidade que determinam a aptidão ao desenvolvimento das culturas.

A aptidão e o zoneamento da palma forrageira para o município de Recife foi realizado baseando-se nos resultados obtidos na tabela 2 e 5 comparando-as com as condições exigidas pela cultura conforme tabela 2. Para o zoneamento e aptidão climática da cultura do caju aplicaram-se os informes das tabelas 3 e 4 .

Segundo Toledo et al. (2009) a aptidão climática de uma região é determinada com base na agregação da precipitação, temperatura e altitude local, sendo de grande importância sob o aspecto própria das culturas, geradora de recursos a agricultura.

\section{Conclusões}

Para o grande Recife as atividades fisiológicas da palma forrageira são bastantes restritas devido às condições inadequadas da disponibilidade de temperatura e do índice de umidade, como foi verificado apresentando-se dentro da faixa restrita ou inapta ao desenvolvimento da cultura.

A técnica de classificação e aptidões climática utilizando dos índices de deficiência hídricas para o município Recife não fornecem subsídios de alta confiabilidade para a classificação e aptidão do caju.

As classificações e aptidões climáticas de Thornthwaite (1948) e Thornthwaite e Mather (1955) consentiram separar eficazmente os climas das áreas em estudo. 
A determinação dos componentes do balanço hídrico permitiu um maior conhecimento da realidade climática da área estudada, ao mesmo tempo em que oferece condições de compatibilização entre a água retida no solo e as diferentes formas de utilização do mesmo, objetivando a minimização dos riscos para a agropecuária e para as populações.

\section{Agradecimentos}

A Coordenação de Aperfeiçoamento de Pessoal de Nível Superior (CAPES) pela concessão de bolsa de Pós-doc e pela pesquisa em desenvolvimento e ao departamento de Engenharia Ambiental.

\section{Referências}

AGUIAR, M.J.N.; SOUSA NETO, N.C.; BRAGA, C.C.; BRITO, J.I.B.; SILVA, E.D.V.; SILVA, F.B.R.; BURGOS, N.; VAREJÃO-SILVA, M.A.; COSTA, C.A.R. Zoneamento pedoclimático para a cultura do cajueiro (Anacardium occidentale L.) no Nordeste do Brasil e Norte de Minas Gerais. Fortaleza: Embrapa Agroindústria Tropical/ Recife: Embrapa-CNPS-ERP-NE, 30p. (Embrapa Agroindústria Tropical. Boletim de Pesquisa, 27). 2000.

ARAÚJO, L. E. Análise estatística de chuvas intensas na bacia hidrográfica do rio Paraíba. Dissertação de mestrado. UFCG, 2006.

ARAÚJO, L. F.; OLIVEIRA, L. S.C. Equilíbrio higroscópico da palma forrageira: Relação com a umidade ótima para fermentação sólida. Revista Brasileira de Engenharia Agrícola e Ambiental, vol.9. n 3. P.379-384. 2005.

BERGAMASCHI, H.. Distribuição hídrica no período crítico do milho e produção de grãos. Pesq. agropec. bras. 39p. 831-839. 2004

BLAIN, G. Considerações estatísticas relativas à oito séries de precipitação pluvial da Secretaria de Agricultura e Abastecimento do Estado de São Paulo, Revista Brasileira de Meteorologia, 24,p.1223. 2009.

BEZERRA, B.G.; ARAÚJO, J.S.; PEREIRA, D.D.; LAURENTINO, G.Q.; SILVA, L.L. Zoneamento agroclimático da palma forrageira (Opuntia sp.) para o estado da Paraíba. Revista Brasileira de Engenharia Agrícola e Ambiental, v. 18, n. 7, p. 755-761, 2014.

ESPINOZA, E.S. Distúrbios nos ventos de leste no Atlântico tropical. Dissertação de Mestrado. São José dos Campos, INPE, 1996.

GUERRA, M.G.; MAIA, M.O.; MEDEIROS, H.R.; LIMA, G.F.C.; AGUIAR, E.M.; GARCIA, L.R.U.C. Produção de novos genótipos de palma forrageira no Estado do Rio Grande do Norte. In: 42a Reunião 
Anual da Sociedade Brasileira de Zootecnia, 2005, Goiânia-GO. Anais... CD-ROM, Goiânia-GO, 2005.

INMET - Instituto Nacional de Meteorologia. Disponível em: < http://www.inmet.gov.br/portal/> Acesso em: 24 Mai. 2016.

KÖPPEN, W.; GEIGER, R. “Klimate der Erde. Gotha: Verlag Justus Perthes”. Wall-map 150cmx200cm. 1928.

KOUSKY, V. E.; Frontal influences on northeast Brazil, Monthly Weather Review, v.107. n. 9. p.1140$1153,1979$.

KOUSKY, V. E.; GAN, M. A. Upper tropospheric cyclones vórtices in the tropical south atlantic. Tellus, v.33: p.538-551, 1981.

HORIKOSHI, A.S.; FISCH, G. Balanço Hídrico Atual e Simulações para Cenários Climáticos Futuros no Município de Taubaté, SP, Brasil. Revista Ambiente e Água - An Interdisciplinary Journal of Applied Science, v.2. n.2. 2007.

MARENGO, J.A.; SOARES, W.R.; SAULO, C.; NICOLINI, M. Climatology of the low-level Jet East of the Andes as Derived from NCEP-NCAR Reanalyses: Characteristics and Temporal Variability. Journal of Climate, v. 17, n. 12, p. 2261 - 2280, 2004.

MEDEIROS, R. M.; MATOS, R. M.; SILVA, P. F.; SILVA, J. A. S. Caracterização climática e diagnóstico da aptidão agroclimática de culturas para Barbalha - CE. Revista Enciclopédia Biosfera, v. 11 n. 21 ; p. 461-476, 2015.

MEDEIROS, R. M. Elaboração de programa computacional em planilhas eletrônicas do Balanço hídrico. 2016.

MEDEIROS, R. M.; SANTOS, D. C.; SOUSA, F. A. S.; GOMES FILHO, M. F. Análise Climatológica, Classificação Climática e Variabilidade do Balanço Hídrico Climatológico na Bacia do Rio Uruçuí Preto, PI. Revista Brasileira de Geografia Física. Recife - PE, v.6, p.652-664, 2013.

MOURA, M.S.B.; SOUZA, L.S.B.; SILVA, T.G.F.; SÁ, I.I.S. Zoneamento agroclimático da palma forrageira para o estado de Pernambuco. Petrolina: Embrapa Semiárido. 26p. Documentos 242. 2011.

OLIVEIRA, G.B.; ALCÂNTARA, C.R.; SILVA, F.P. Balanço hídrico e classificação climática de Thorthwaite e Mather (1995) para a região de Barbalha - Ceará. I Workshop Internacional Sobre Água no Semiárido Brasileiro. Anais... Campina Grande, 2013.

OLIVEIRA NETO, S.N.; REIS, G.G.; REIS, M.G.F.; LEITE, H.G.; COSTA, J.M.N. Estimativa de temperaturas mínima, média e máxima do território brasileiro situado entre 16 e $24^{\circ}$ latitude sul e 48 e $60^{\circ}$ longitude oeste. Engenharia na Agricultura, Viçosa, MG, v. 10, n. 1-4, p. 57-61, 2002. 
OMETTO, J. C. Bioclimatologia vegetal. São Paulo: Ceres, 1981.

PEREIRA, A. R.; ANGELOCCI, L.R.; SENTELHAS, P.C. Meteorologia Agrícola. Departamento de Ciências Exatas, p. 173, Piracicaba, SP. 2007.

PEREIRA, A R.; ANGELOCCI, L. R.; SENTELHAS, P. C. Agrometeorologia: fundamentos e aplicações práticas. Guaíba: Livraria e Editora Agropecuária, p.478, 2002.

PINTO, S.A.; ASSAD, E.D.; ZULLO JÚNIOR, J.; ÁVILA, A.M.H. Variabilidade climática. In: HAMADA, E. (Ed.). Água, agricultura e meio ambiente no Estado de São Paulo: avanços e desafios. Jaguariúna: Embrapa Meio Ambiente, Cap. CDROM. 2011

ROCHA, J.E.S. Palma forrageira no Brasil: o estado da arte. EMBRAPA Caprinos e Ovinos. 40p. (Documentos, 106). 2012.

SANTOS, A.S.; GOMES, H.B.; AMORIM, R.F.C.; AMORIM, R.C.F.; PONTES, E.G.S.; MEDEIROS, F.C. Estudo da Climatologia dos Ventos Através dos Dados de Reanálises: Período 1970-2002, e Sua Relação com a Precipitação para o Estado de Alagoas nos Anos 1992/94. In: XIII Congresso Brasileiro de Meteorologia, 2001, Fortaleza - CE. Meteorologia e o Desenvolvimento Sustentável, 2001.

SANTOS, G. O.; HERNANDEZ, F. B. T.; ROSSETTI, J. C. Balanço hídrico como ferramenta ao planejamento agropecuário para a região de Marinópolis, noroeste do estado de São Paulo. Revista Brasileira de Agricultura Irrigada, v. 4, n. 3, p.142 - 149, 2010.

SOUZA, L.S.B.; MOURA, M.S.B.; SILVA, T.G.F.; SOARES, J.M.; CARMO, J.F.A.; BRANDÃO, E. O. Indicadores climáticos para o zoneamento agrícola da palma forrageira (Opuntia sp.). In: Jornada de Iniciação Científica da Embrapa Semiárido, 3, 2008, Petrolina. Anais...Petrolina: Embrapa SemiÁrido, p.23-28. Documentos 210. 2008.

SEVERINO, R.P. Busca de produtos naturais como inibidores específicos de enzimas. Tese (Doutorado em Ciências - Química Inorgânica), Universidade Federal de São Carlos, São Carlos. 2008.

THORNTHWAITE, C.W. An approach towards a rational classification of climate. Geographical Review, London, v. 38, p. 55 - 94, 1948.

THORNTHWAITE, C.W.; MATHER, J.R. The water balance. Publication in Climatology $\mathrm{N}^{\circ} 8$, Laboratory of Climatology, Centerton, N.J. 1955.

TOLEDO, J.V.; MARTINS, L.D.; KLIPPEL, V.H.; PEZZOPANE, J.E.M.; TOMAZ, M.A.; AMARAL, J.F.T. Zoneamento agroclimático para a cultura do pinhão manso (Jatropha CurcasL.) e da mamona (Ricinus Communis L.) no estado do Espírito Santo. Agropecuária Científica no Semi-Árido, v. 05, p. 41 - 51, 2009. 
UVO, C.R.B. A zona de convergência intertropical (ZCIT) e sua relação com a precipitação na região norte e nordeste brasileiro. Dissertação de Mestrado. INPE. São José dos Campos, 1989.

WOLLMANN, C.A.; GALVANI, E. Zoneamento agroclimático: linhas de pesquisa e caracterização teórica-conceitual. Sociedade e Natureza, v. 25, p. 179-190, 2013. 